\title{
High prevalence of anaemia and limited use of therapy in cancer patients: a Belgian survey (Anaemia Day 2008)
}

\author{
Natacha Verbeke • Yves Beguin • Hans Wildiers • \\ J. L. Canon • Greet Bries • Andre Bosly • \\ Simon Van Belle
}

Received: 26 February 2010 / Accepted: 11 November 2010/Published online: 25 November 2010

(C) Springer-Verlag 2010

\begin{abstract}
Objectives The aim of this study is to provide relevant and accurate information on prevalence and treatment patterns of anaemia in Belgian cancer patients.

Methods The Anaemia Day 2008 survey was a single visit, multi-centre, non-interventional study in adult cancer patients under systemic therapy (chemotherapy, hormonal, immunological and/or targeted therapy) and/or radiotherapy. Efforts were made to enrol the maximum number of patients seen in each centre that day. Patients signed an informed consent and relevant data were collected from their files, i.e. disease and
\end{abstract}

Natacha Verbeke and Yves Beguin equally contributed

N. Verbeke $(\bowtie) \cdot S$. Van Belle

Department of Medical Oncology, University Hospital Ghent,

De Pintelaan 185,

9000, Ghent, Belgium

e-mail: Natacha.Verbeke@Uzgent.be

\section{Y. Beguin}

Department of Haematology, University Hospital of Liege,

Liege, Belgium

H. Wildiers

Department of Oncology, University Hospital of Leuven, Leuven, Belgium

\section{J. L. Canon}

Department of Haematology-Oncology,

Grand Hopital de Charleroi,

Charleroi, Belgium

\section{G. Bries}

Department of Haematology, Hospital Virga Jesse of Hasselt, Hasselt, Belgium

\section{A. Bosly}

Department of Haematology, UCL Mont-Godinne,

Yvoir, Belgium disease stage, cancer therapy and anti-anaemic treatment, including transfusions and the use of erythropoietin stimulating agents (ESA). A blood count of each included patient was performed. Haemoglobin $(\mathrm{Hb})$ values (grams per decilitre) were classified into four categories to assess the severity of anaemia, as defined by WHO: no anaemia: $\mathrm{Hb} \geq 12 \mathrm{~g} / \mathrm{dL}$; mild $10 \leq \mathrm{Hb} \leq 11.9 \mathrm{~g} / \mathrm{dL}$; moderate $8 \leq \mathrm{Hb} \leq 9.9 \mathrm{~g} / \mathrm{dL}$; severe $\mathrm{Hb}<$ $8 \mathrm{~g} / \mathrm{dL}$. Univariate and multivariate analyses were carried out with anaemia as the dependent variable.

Results A total of 1,403 eligible patients aged $63 \pm 13$ years (mean age $\pm \mathrm{SD}$ ) were enrolled in 106 oncology or haematology centres. The mean $\mathrm{Hb}$ level $( \pm \mathrm{SD})$ was $11.6 \mathrm{~g} / \mathrm{dL}( \pm 1.8 \mathrm{~g} / \mathrm{dL})$ and the prevalence of anaemia $(\mathrm{Hb}<12 \mathrm{~g} / \mathrm{dL})$ was $55.7 \%(95 \%$ CI, 53.1-58.3\%), respectively, $35.9 \%$ mild, $17.8 \%$ moderate and $2.1 \%$ severe anaemia. Anaemia was more frequent in females than in males, and in patients with haematological malignancies (73.4\%) than in those with solid tumours $(51.4 \%$; $p<0.001)$. Anaemia prevalence was higher in hospitalised patients $(75.5 \%)$ compared to those seen in one-day-clinic $(54.3 \%)$ or in consultation $(33.9 \% ; p<0.001)$, and in patients treated with chemotherapy $(61.3 \%)$ compared to those receiving radiotherapy $(34.4 \%)$ or hormonal therapy $(19.5 \% ; p<0.001)$. There was a clear correlation between severity of anaemia and WHO performance status $(p<$ 0.001 ). Among anaemic patients, $53.1 \%$ received no treatment (mean $\mathrm{Hb} 10.8 \pm 0.9 \mathrm{~g} / \mathrm{dL}$ ). Among the anaemic patients who received therapy for their anaemia (mean $\mathrm{Hb}$ $9.7 \pm 1.1 \mathrm{~g} / \mathrm{dL}$ ), the most frequent treatments were RBC transfusions (42\%), ESA (34.6\%), transfusions+ESA (12\%), ESA+iron (7.9\%) and iron alone (3.5\%). Comparison to the ECAS survey shows that there has been no major change in attitude towards anaemia management in the last decade.

Conclusion This survey shows that cancer-related anaemia is still frequently observed in cancer patients. Even if in our 
study ESA were used more frequently than about 10 years ago, still a large amount of anaemic patients who could be treated for anaemia according to EORTC guidelines, were not.

Keywords Anaemia $\cdot$ Survey Erythropoietin stimulating agents (ESA)

\section{Introduction}

Anaemia is common in patients with malignancy, particularly if under chemotherapy [1]. The impact of anaemia on the physical and psychological health status of cancer patients is well known [1,2]. Therefore, optimal management of anaemia appears to be an important component of cancer treatment. Particularly important may be the effect of mild-to-moderate anaemia on patients who might not be treated according to the European Organisation for Research and Treatment of Cancer (EORTC) guidelines [3], patients with haemoglobin between 10.0 and $11.9 \mathrm{~g} / \mathrm{dL}$.

Recent data on prevalence and incidence of anaemia in cancer patients, particularly within the routine practice of individual countries, are almost non-existing. This study describes the methodology of the Anaemia Day and provides patient data that focus on the prevalence of anaemia, the effect of mild, moderate and severe anaemia on performance status, and anaemia treatment patterns.

\section{Material and methods}

Study design The "Anaemia Day 2008" survey is a one visit only, multi-centre and non-interventional study in cancer patients presenting at Belgian oncology and haematology centres. Inclusion criteria were: age 18 years or older, bearing a solid tumour or a haematological malignancy, being under systemic therapy and/or radiotherapy, having a blood count foreseen the day of the scheduled visit and having given a written informed consent.

Data collection The following data were collected: date of the visit, age, geographical region, gender, WHO performance status, site of visit (hospitalisation, one-day hospital unit, consultation), reason of visit (follow-up, active treatment, supportive care, other), date of the initial diagnosis of cancer, age of the patient at diagnosis. The tumour was classified as solid or haematological and the current tumour extension was reported as primary, locally advanced or metastatic. Recent therapy (last 4 weeks before the recorded visit) was reported as chemotherapy, radiotherapy, hormonal therapy, or other (immunological therapy, targeted therapy, other). For chemotherapy, the intention of treatment (adjuvant, neoadjuvant, advanced stage), the actual number of cycles and the schedule (containing platinum, anthracyclines, taxanes or others) were also recorded.

Blood haemoglobin $(\mathrm{Hb})$ levels (grams per decilitre) were measured on the day of visit and classified into four categories in order to assess the severity of anaemia: none, $\mathrm{Hb} \geq 12 \mathrm{~g} / \mathrm{dL}$; mild, $10 \leq \mathrm{Hb} \leq 11.9 \mathrm{~g} / \mathrm{dL}$; moderate, $8 \leq \mathrm{Hb} \leq$ $9.9 \mathrm{~g} / \mathrm{dL}$; severe, $\mathrm{Hb}<8 \mathrm{~g} / \mathrm{dL}$. Anaemia-related symptoms occurring during the 4 weeks preceding the day of the survey were also recorded. The following information about antianaemic treatment was collected: time when treatment was started (during past 4 weeks or on day of survey), type of treatment (none, RBC transfusion, erythropoiesis-stimulating agents (ESA), iron supplementation), the $\mathrm{Hb}$ level at initiation of treatment and the targeted $\mathrm{Hb}$ level.

Statistical analyses The primary endpoint of the study was prevalence and severity of anaemia (mild, moderate, severe) in Belgian cancer patients treated with systemic therapy and/or radiotherapy in oncology/haematology centres. Secondary endpoints included the description of the characteristics of cancer patients as well as their current management of anaemia.

Results were expressed as mean \pm standard deviation (SD), median and range for quantitative variables. The relationship between two variables was assessed by the correlation coefficient or by the chi-square test in case of two categorical variables. Mean values from two groups were compared by the Student $t$ test (corrected for unequal variances if necessary) or by a non-parametric test (e.g. Wilcoxon test) when the variable was not normally distributed. Analyses of variance or the non-parametric Kruskal-Wallis test were applied for the comparison of several groups. The classical chi-square test for contingency tables was used for comparing proportions.

Logistic regression analysis was used to measure the association between anaemia and a set of covariates. The odds ratio (OR) was computed with its $95 \%$ confidence interval (CI) to measure the association between the risk of anaemia and the covariates. Ordinal logistic regression analysis was also used to relate the severity of anaemia with the same set of covariates.

Results were considered to be significant at the $5 \%$ significant level $(p<0.05)$.

\section{Results}

A total of 1,403 eligible patients aged $63.1 \pm 13.0$ years were enrolled in 106 oncology or haematology centres. The mean time $( \pm \mathrm{SD})$ since first diagnosis of cancer was $2.1 \pm$ 
3.2 years (range, $0-24$ years). Table 1 summarises the demographics and patient characteristics.

For the 1,403 included patients, the prevalence of anaemia was $55.7 \%$ with a mean $\mathrm{Hb}$ level $( \pm \mathrm{SD})$ of 11.6 $\pm 1.8 \mathrm{~g} / \mathrm{dL}$. The classification of the cancer patients according to their haemoglobin levels revealed that $44.3 \%$ were not anaemic, $35.9 \%$ presented a mild anaemia, $17.8 \%$ a moderate anaemia and $2.1 \%$ a severe anaemia.

Table 2 displays anaemia prevalence by tumour type and extent of cancer. Only $13.8 \%$ of patients with solid tumours had moderate or severe anaemia, while the proportion was

Table 1 Clinical characteristics of the 1,403 patients enrolled in the study

\begin{tabular}{|c|c|}
\hline Variable & Frequency (proportion, \%) \\
\hline \multicolumn{2}{|l|}{ Gender } \\
\hline Men & $703(50.1)$ \\
\hline Women & $700(49.9)$ \\
\hline \multicolumn{2}{|l|}{ Site of patient contact } \\
\hline Hospitalisation & $354(25.2)$ \\
\hline One-day clinic & $775(55.2)$ \\
\hline Consultation & $274(19.5)$ \\
\hline \multicolumn{2}{|l|}{ WHO performance } \\
\hline 0 & $454(32.4)$ \\
\hline 1 & $636(45.4)$ \\
\hline 2 & $236(16.8)$ \\
\hline 3 & $60(4.3)$ \\
\hline 4 & $16(1.1)$ \\
\hline \multicolumn{2}{|l|}{ Purpose of visit } \\
\hline Chemotherapy & $883(62.9)$ \\
\hline Radiotherapy & $100(7.1)$ \\
\hline Follow-up & $260(18.5)$ \\
\hline Supportive care & $112(8.0)$ \\
\hline Complication management & $85(6.1)$ \\
\hline $\mathrm{RBC}$ transfusion & $33(2.4)$ \\
\hline Other & $58(4.1)$ \\
\hline \multicolumn{2}{|l|}{ Primary tumour } \\
\hline Solid tumour & $1,125(80.2)$ \\
\hline Breast & $258(25.3)$ \\
\hline Colorectal & $402(35.7)$ \\
\hline Urogenital & $72(6.4)$ \\
\hline Lung & $226(20.1)$ \\
\hline Gynaecologic & $59(5.2)$ \\
\hline Head-and-neck & $44(3.9)$ \\
\hline Other & $37(3.3)$ \\
\hline Haematological tumour & $278(19.8)$ \\
\hline Lymphoma/Myeloma & $155(55.8)$ \\
\hline Leukaemia & $88(31.7)$ \\
\hline Myelodysplasia & $19(6.8)$ \\
\hline Other & $16(5.8)$ \\
\hline
\end{tabular}

$44.2 \%$ in those with haematological malignancies $(p<$ 0.001). In solid tumour patients, the level of anaemia differed significantly according to the location of the primary tumour, with more moderate and severe anaemia in patients with gynaecological and head-and-neck tumours $(p<0.0001)$. For haematological malignancies, more moderate and severe anaemia were reported in patients with myelodysplastic syndromes $(p<0.0001)$. Anaemia was significantly associated with the extent of cancer. Patients with metastasis or locally advanced cancer had significantly more often moderate to severe anaemia than patients with only a localised solid tumour.

There was a trend for higher incidence of anaemia in female. From a multivariate standpoint, female were 1.8 times more at risk of anaemia than men.

Table 3 shows the prevalence of anaemia according to the treatment received. When analysed by type of treatment at enrolment, $61.3 \%$ of patients receiving chemotherapy, $34.4 \%$ of those receiving radiotherapy and $19.5 \%$ of those receiving hormonal therapy were anaemic.

There was a clear correlation between the severity of anaemia and WHO performance status $(p<0.0001)$. There were more patients at enrolment with poor-performance status at lower $\mathrm{Hb}$ levels than at higher $\mathrm{Hb}$ levels. WHO scores of $2-4$ were recorded for $65 \%$ of patients with $\mathrm{Hb}<$ $8.0 \mathrm{~g} / \mathrm{dL}, 48 \%$ of those with $\mathrm{Hb}$ between 8.0 and $9.9 \mathrm{~g} / \mathrm{dL}$, $22 \%$ of those with $\mathrm{Hb}$ between 10.0 and $11.9 \mathrm{~g} / \mathrm{dL}$ and $1 \%$ of those with $\mathrm{Hb}>12 \mathrm{~g} / \mathrm{dL}$ (Table 4).

Of patients who were ever anaemic (the day of survey or past 4 weeks preceding the visit; $n=782$ ), $53.1 \%$ received no treatment. The majority $(83 \%)$ of untreated anaemic patients had $\mathrm{Hb}$ levels between 10.0 and $11.9 \mathrm{~g} / \mathrm{dL} ; 17 \%$ had $\mathrm{Hb}$ levels between 8.0 and $9.9 \mathrm{~g} / \mathrm{dL}$, and $0.1 \%$ had $\mathrm{Hb}$ levels $<8 \mathrm{~g} / \mathrm{dL}$.

Table 5 shows the percentage of patients who received treatment for their anaemia. For the $46.9 \%$ of patients who received treatment, the most frequent therapy was transfusion, either alone (42\%) or in combination with ESA (12\%). The frequencies of ESA treatment alone or with iron were $35 \%$ and $8 \%$, respectively, and that of iron alone was 3.5\%. The mean $\mathrm{Hb}$ level for initiating treatment was $9.7 \mathrm{~g} / \mathrm{dL}$ in our study, with the level for transfusion being $9.2 \mathrm{~g} / \mathrm{dL}$ and the level for ESA being $10.2 \mathrm{~g} / \mathrm{dL}$.

\section{Discussion}

This survey shows that anaemia is still frequently observed in Belgian cancer patients under treatment, with a general prevalence of $55.7 \%$, including $20 \%$ with moderate to severe anaemia. Anaemia was more frequent in patients with haematological tumours $(73.4 \%)$ than in patients with solid tumours $(51.4 \%)$. Among solid tumour patients, 
Table 2 Distribution of the grade of anaemia according to the type of primary tumour and tumour extension

\begin{tabular}{lcccc}
\hline & No anaemia & Mild anaemia & Moderate anaemia & Severe anaemia \\
\hline Primary tumour & & & & \\
Solid tumour & $547(48.6)$ & $423(37.6)$ & $143(12.7)$ & $12(1.1)$ \\
Breast & $159(55.8)$ & $92(32.3)$ & $32(11.2)$ & $2(0.7)$ \\
Colorectal & $212(52.7)$ & $153(38.1)$ & $35(8.7)$ & $2(0.5)$ \\
Urogenital & $44(61.1)$ & $19(26.4)$ & $8(11.1)$ & $1(1.4)$ \\
Lung & $82(36.4)$ & $101(44.7)$ & $38(16.8)$ & $5(2.2)$ \\
Gynaecologic & $16(28.1)$ & $28(47.5)$ & $13(22.0)$ & $2(3.4)$ \\
ORL & $17(38.6)$ & $17(38.6)$ & $10(22.7)$ & $0(0.0)$ \\
Other & $17(46.0)$ & $13(35.1)$ & $7(18.9)$ & $1(1.4)$ \\
Haematological tumour & $74(26.6)$ & $81(29.1)$ & $106(38.1)$ & $17(6.1)$ \\
Lymphoma/myeloma & $42(27.1)$ & $57(36.8)$ & $52(33.6)$ & $4(2.6)$ \\
Leukaemia & $20(22.7)$ & $21(23.9)$ & $41(46.6)$ & $6(6.8)$ \\
Myelodysplasia & $1(5.3)$ & $3(15.8)$ & $10(52.6)$ & $5(26.3)$ \\
Other & $11(68.8)$ & $0(0.0)$ & $3(18.8)$ & $2(12.5)$ \\
Tumour extent(solid tumours) & & & & \\
Primary & $176(65.4)$ & $84(31.2)$ & $9(3.4)$ & $0(0.0)$ \\
Locally advanced & $86(45.5)$ & $71(37.6)$ & $29(15.3)$ & $3(1.6)$ \\
Metastatic & $285(42.7)$ & $268(40.2)$ & $105(15.7)$ & $9(1.4)$ \\
\hline
\end{tabular}

anaemia was more severe in patients with gynaecological and head-and-neck tumours. Among patients with haematological malignancies, anaemia was more prominent in those with myelodysplastic syndromes.

The prevalence of anaemia found in our survey is higher than in previous reports. In Japanese and Turkish studies, $44 \%$ of the patients were anaemic at the start of their chemotherapy [4, 5]. The prevalence of anaemia at enrolment in the European and Australian Cancer Anaemia surveys (ECAS, ACAS) was 39\% and 35\%, respectively, with $10 \%$ and $8 \%$ having moderate to severe anaemia [1, 6]. This difference could be explained by the exclusion of untreated patients in the ECAS and ACAS studies. In the ECAS study, the prevalence of anaemia among patients receiving chemotherapy was $62.7 \%$, a figure comparable to ours.

We observed a clear correlation between anaemia and low-performance status. More than half of the patients with severe anaemia had a WHO score of 2-4, but performance scores of 2-4 were also noted for $22 \%$ of patients with
Table 3 Distribution of the grade of anaemia according to the type of treatment

\begin{tabular}{lrccr}
\hline Treatment & No anaemia & Mild anaemia & Moderate anaemia & Severe anaemia \\
\hline Chemotherapy & $435(38.7)$ & $455(40.5)$ & $208(18.5)$ & $26(2.3)$ \\
Type of chemotherapy & & & & \\
Neoadjuvant & $97(44.1)$ & $91(41.4)$ & $28(12.7)$ & $4(1.8)$ \\
Adjuvant & $38(45.8)$ & $29(34.9)$ & $16(19.3)$ & $0(0.0)$ \\
Advanced stage & $278(37.6)$ & $306(41.4)$ & $138(18.7)$ & $18(2.4)$ \\
Components & & & & \\
Platinum-based & $162(39.4)$ & $178(43.3)$ & $64(15.6)$ & $1(1.7)$ \\
Taxane-based & $35(31.3)$ & $55(49.1)$ & $21(18.8)$ & $7(0.9)$ \\
Anthracyclines-based & $47(31.8)$ & $65(43.9)$ & $29(19.6)$ & $13(2.3)$ \\
Other & $226(40.4)$ & $209(37.4)$ & $111(19.9)$ & $0(0.0)$ \\
Radiotherapy & $103(65.5)$ & $35(22.3)$ & $19(12.1)$ & $0(0.0)$ \\
Hormonotherapy & $66(80.5)$ & $10(12.2)$ & $6(7.3)$ & $2(2.8)$ \\
Immunological therapy & $36(50.0)$ & $17(23.6)$ & $17(23.6)$ & $4(3.4)$ \\
Targeted therapy & $57(48.3)$ & $35(29.7)$ & $22(18.6)$ & $2(3.0)$ \\
Other & $23(34.3)$ & $18(26.9)$ & $24(35.8)$ & \\
\hline
\end{tabular}


Table 4 Distribution of the grade of anaemia according to the WHO performance status

\begin{tabular}{lcrrr}
\hline $\begin{array}{l}\text { WHO } \\
\text { performance } \\
\text { status }\end{array}$ & $\begin{array}{l}\text { No } \\
\text { anaemia }\end{array}$ & $\begin{array}{l}\text { Mild } \\
\text { anaemia }\end{array}$ & $\begin{array}{l}\text { Moderate } \\
\text { anaemia }\end{array}$ & $\begin{array}{l}\text { Severe } \\
\text { anaemia }\end{array}$ \\
\hline 0 & $286(63.0)$ & $146(32.2)$ & $20(4.4)$ & $2(0.4)$ \\
1 & $274(43.1)$ & $245(38.5)$ & $109(17.1)$ & $8(1.3)$ \\
2 & $50(21.2)$ & $89(37.7)$ & $82(34.8)$ & $15(6.4)$ \\
3 & $8(13.3)$ & $20(33.3)$ & $28(46.7)$ & $4(6.7)$ \\
4 & $3(18.8)$ & $4(25.0)$ & $9(56.3)$ & $0(0)$ \\
\hline
\end{tabular}

haemoglobin levels between 10.0 and $11.9 \mathrm{~g} / \mathrm{dL}$. This relationship between anaemia and low-performance status was already demonstrated in the ECAS study and is consistent with the correlation reported between the increase in haemoglobin levels with ESA and the improvement of quality of life [7-9]. In the large trial of Demetri et al., patients who achieved an increase in haemoglobin level of $2 \mathrm{~g} / \mathrm{dL}$ or greater had the largest increase in quality of life, even in the case of progressive disease [7].

Despite evidence that even mild anaemia can adversely affect quality of life, many clinicians still don't treat anaemic patients. In our survey, $53.1 \%$ of the anaemic patients received no treatment for their anaemia. Most of them (35.4\%) had haemoglobin levels between 10.0 and $11.9 \mathrm{~g} / \mathrm{dL}$, but another $15 \%$ of the untreated patients had a haemoglobin level $<10 \mathrm{~g} / \mathrm{dL}$. In the ECAS study, anaemia treatment was initiated in approximately $40 \%$ of anaemic patients [1].

In our survey, the most frequently used treatments were RBC transfusions (42\%), ESA (34.6\%), transfusions+ESA $(12 \%)$, ESA+iron $(7.9 \%)$ or iron alone $(3.5 \%)$. In comparison, in the ECAS and ACAS studies, transfusions were given to $17 \%$ and $36 \%$ and $\mathrm{ESA}$ to $15 \%$ and $2 \%$ of the patients, respectively. The mean haemoglobin level for initiating treatment was $9.7 \mathrm{~g} / \mathrm{dL}$ in our study, with the level

Table 5 Number of anaemic patients who received treatment

\begin{tabular}{llr}
\hline & $n$ & Hb level $(\mathrm{g} / \mathrm{dL})$ \\
\hline Never treated anaemic patients & 415 & $10.8 \pm 0.9$ \\
Treated anaemic patients & 367 & $9.7 \pm 1.1$ \\
Anaemic treatments & & \\
Transfusion & 154 & $9.3 \pm 1.1$ \\
Transfusion+ESA & 44 & $9.5 \pm 1.2$ \\
ESA & 127 & $10.2 \pm 1.0$ \\
ESA+Iron & 29 & $9.8 \pm 1.0$ \\
Iron & 13 & $10.0 \pm 1.1$ \\
\hline
\end{tabular}

Treatment could be given on the day of the visit or in the past 4 weeks for transfusion being $9.2 \mathrm{~g} / \mathrm{dL}$ and that for ESA $10.2 \mathrm{~g} / \mathrm{dL}$. The trigger for initiating transfusions was $9.7 \mathrm{~g} / \mathrm{dL}$ both in the ECAS and ACAS studies $[1,6]$.

Several studies with ESA have raised a number of safety issues, including an increased risk of thromboembolic events and a negative impact on survival [10-12]. In a recent meta-analysis based on individual patient data from randomised trials, the HR for overall mortality was 1.06 (95\% CI, 1.00-1.12) [13]. This meta-analysis also included patients not receiving treatment for their cancer or receiving treatments other than chemotherapy The HR of death was $1.10(95 \%$ CI, 0.98-1.24) in patients treated with chemotherapy and few of the included trials were restricted to the approved indications of ESA, making it difficult to generalise these results.

The EORTC guidelines recommend that ESAs should be initiated at an $\mathrm{Hb}$ level of $9-11 \mathrm{~g} / \mathrm{dL}$ in cancer patients receiving chemotherapy or radiochemotherapy, based on anaemia-related symptoms [3]. And ESA therapy may be considered in selected asymptomatic patients receiving chemotherapy with a $\mathrm{Hb}$ level of $11-11.9 \mathrm{~g} / \mathrm{dL}$ if this would prevent a further decline in $\mathrm{Hb}$. Such a decision should take into account an individual's $\mathrm{Hb}$ level and the type, intensity, and duration of chemotherapy. The aim of treatment with ESA is to achieve an $\mathrm{Hb}$ concentration of about $12 \mathrm{~g} / \mathrm{dL}$, without exceeding this target. For that reason, the new label for ESA suggests to initiate treatment to patients with syptomatic anaemia in order to increase haemoglobin, without exceeding the target of $12 \mathrm{~g} / \mathrm{dL}$.

This study indicates that Belgian physicians respect these recommendations: the $\mathrm{Hb}$ trigger to start ESA treatment was $10.2 \mathrm{~g} / \mathrm{dL}$ and the target was $11.6 \mathrm{~g} / \mathrm{dL}$. Our Belgian treatment patterns are congruent with the findings from the Anaemia Cancer Treatment Study (ACT), where most patients were treated per guidelines [14]. In the ACT study, after treatment with ESA, the $\mathrm{Hb}$ increased by $1.34 \mathrm{~g} / \mathrm{dl}$, without concomitant rise in WHO score. We were not able to analyse the correlation between use of ESA and anaemia-related symptoms because of the design of the study that was a one-day snapshot of a large population of cancer patients. In this survey, only patients under systemic therapy or radiotherapy were included. For this reason, it is impossible to assess potential off-label uses, but as in Belgium reimbursement of ESA is restricted to patients under chemotherapy, such offlabel use would be expected to be very low.

In conclusion, this survey shows that cancer-related anaemia is still frequently observed in patients in Belgium and that it correlates significantly with poor performance status. Even if in our survey ESA were used more frequently than 10 years ago, a significant proportion of patients with moderate and probably symptomatic anaemia who could be treated for anaemia according to the EORTC guidelines did not. 
Acknowledgements This study was sponsored by Amgen Belgium.

Conflicts of Interest There is no conflict of interest.

\section{References}

1. Ludwig H, Van Belle S, Barrett-Lee P et al (2004) The European Cancer Anaemia Survey (ECAS): a large, multinational, prospective survey defining the prevalence, incidence, and treatment of anaemia in cancer patients. Eur J Cancer 40:2293-2306

2. Caro JJ, Salas M, Ward W et al (2001) Anaemia is an independent prognostic factor for survival in patients with cancer. Cancer 91:2214-2221

3. Aapro MS, Link H (2008) September 2007 update on EORTC guidelines and anemia management with erythropoiesis-stimulating Agents. Oncologist 13:33-36

4. Kitano T, Tada H, Nishimura T et al (2007) Prevalence and incidence of anaemia in Japanese cancer patients receiving outpatient chemotherapy. Int J Hematol 86:37-41

5. Tas F, Eralp Y, Basaran M et al (2002) Anemia in oncology practice: relation to diseases and their therapies. Am J Clin Oncol 25:371-379

6. Seshadri T, Prince HM, Bell DR et al (2005) The Australian Cancer Anaemia Survey: a snapshot of anaemia in adult patients with cancer. Med J Aust 182:453-457

7. Demetri GD, Kris M, Wade J et al (1998) Quality-of-life benefit in chemotherapy patients treated with epoetin alfa is independent of disease response or tumor type: results from a prospective community oncology study. J Clin Oncol 16:3412-3425

8. Pelegri A (2007) Impact of erythropoietin treatment on the quality of life of oncologic patients. Clin Transl Oncol 9:645651

9. Glaspy J, Bukowski R, Steinberg D et al (1997) Impact of therapy with epoetin alfa on clinical outcomes in patients with nonmyeloid malignancies during cancer chemotherapy in community oncology practice. J Clin Oncol 15:1218-1234

10. Bohlius J, Wilson J, Seindenfeld J et al (2006) Recombinant human erythropoietins and cancer patients: updated meta-analysis of 57 studies including 9353 patients. J Natl Cancer Inst 98:708714

11. Bennet CL, Silver S, Djulbegovic B et al (2008) Venous thromboembolism and mortality associated with recombinant erythropoietin and darbepoetin administration for the treatment of cancer-associated anaemia. JAMA 299:914-924

12. Henke M, Mattern D, Pepe M et al (2006) Do erythropoietin receptors on cancer cells explain unexpected clinical findings? J Clin Oncol 24:4708-4713

13. Bohlius J, Schmidlin K, Brillant C et al (2009) Recombinant human erythropoiesis-stimulating agents and mortality with cancer: a meta-analysis of randomised trials. Lancet 373:15321542

14. Ludwig H, Aapro M, Bokemeyer C et al (2009) Treatment patterns and outcomes in the management of anaemia in cancer patients in Europe: findings from the Anaemia Cancer Treatment (ACT) study. Eur J Cancer 45:1603-1615 